\title{
Exacerbation of cigarette smoke-induced pulmonary inflammation by Staphylococcus aureus Enterotoxin B in mice
}

Wouter Huvenne ${ }^{1 \dagger}$, Ellen A Lanckacker ${ }^{2^{*} \dagger}$, Olga Krysko ${ }^{1}, K_{\text {Ken R Bracke }}^{2}$, Tine Demoor ${ }^{3}$, Peter W Hellings ${ }^{4}$, Guy G Brusselle², Guy F Joos², Claus Bachert ${ }^{1}$ and Tania Maes $^{2}$

\begin{abstract}
Background: Cigarette smoke (CS) is a major risk factor for the development of COPD. CS exposure is associated with an increased risk of bacterial colonization and respiratory tract infection, because of suppressed antibacterial activities of the immune system and delayed clearance of microbial agents from the lungs. Colonization with Staphylococcus aureus results in release of virulent enterotoxins, with superantigen activity which causes T cell activation.
\end{abstract}

Objective: To study the effect of Staphylococcus aureus enterotoxin B (SEB) on CS-induced inflammation, in a mouse model of COPD.

Methods: C57/Bl6 mice were exposed to CS or air for 4 weeks (5 cigarettes/exposure, 4x/day, 5 days/week). Endonasal SEB $(10 \mu \mathrm{g} / \mathrm{ml})$ or saline was concomitantly applied starting from week 3, on alternate days. $24 \mathrm{~h}$ after the last CS and SEB exposure, mice were sacrificed and bronchoalveolar lavage (BAL) fluid and lung tissue were collected.

Results: Combined exposure to CS and SEB resulted in a raised number of lymphocytes and neutrophils in BAL, as well as increased numbers of $\mathrm{CD}^{+} \mathrm{T}$ lymphocytes and granulocytes in lung tissue, compared to sole CS or SEB exposure. Moreover, concomitant CS/SEB exposure induced both IL-13 mRNA expression in lungs and goblet cell hyperplasia in the airway wall. In addition, combined CS/SEB exposure stimulated the formation of dense,

organized aggregates of B- and T- lymphocytes in lungs, as well as significant higher CXCL-13 (protein, mRNA) and CCL19 (mRNA) levels in lungs.

Conclusions: Combined CS and SEB exposure aggravates CS-induced inflammation in mice, suggesting that Staphylococcus aureus could influence the pathogenesis of COPD.

\section{Background}

Cigarette smoking is associated with an increased risk of bacterial colonization and respiratory tract infection, because of suppressed antibacterial activities of the immune system and delayed clearance of microbial agents from the lungs [1]. This is particularly relevant in COPD patients, where bacterial colonization in the lower respiratory tract has been shown [2]. These

\footnotetext{
* Correspondence: ellen.lanckacker@ugent.be

+ Contributed equally

${ }^{2}$ Department of Respiratory Medicine, Ghent University Hospital and Ghent University, Ghent, Belgium

Full list of author information is available at the end of the article
}

bacteria are implicated both in stable COPD and during exacerbations, where most commonly pneumococci, Haemophilus influenza, Moraxella catarrhalis and Staphylococcus aureus (S. aureus) are found [3]. Interestingly, colonization with $S$. aureus may embody a major source of superantigens as a set of toxins are being produced including S. aureus enterotoxins (SAEs) [4]. These toxins activate up to $20 \%$ of all $\mathrm{T}$ cells in the body by binding the human leukocyte antigen (HLA) class II molecules on antigen-presenting cells (APCs) and specific $\mathrm{V}$ beta regions of the $\mathrm{T}$ cell receptor [5]. Between 50 and $80 \%$ of $S$. aureus isolates are positive for at least one superantigen gene, and close to $50 \%$ of

\section{() Biomed Central}


these isolates show superantigen production and toxin activity [6].

During the last few years, it became increasingly clear that SAEs are known to modify airway disease [7], like allergic rhinitis [8], nasal polyposis [9] and asthma [10]. Furthermore, studies have shown a putative role for SAEs in patients suffering from the atopic eczema/dermatitis syndrome (AEDS), where colonization with $S$. aureus is found more frequently (80-100\%) compared to healthy controls (5-30\%) [11], and S. aureus isolates secrete identifiable enterotoxins like Staphylococcus aureus enterotoxin A and B (SEA, SEB) and toxic shock syndrome toxin (TSST)-1. Until now, evidence for SAE involvement in the pathogenesis of upper airway disease like chronic rhinosinusitis with nasal polyposis (CRSwNP), arises from the finding that IgE against SEA and SEB has been demonstrated in nasal polyps [12] and levels of SAE-specific IgE in nasal polyposis correlated with markers of eosinophil activation and recruitment [13]. Similarly, in COPD patients, a significantly elevated IgE to SAE was found, pointing to a possible disease modifying role in COPD, similar to that in severe asthma [14]. Moreover, we have recently demonstrated the pro-inflammatory effect of SEB on human nasal epithelial cells in vitro, resulting in augmented granulocyte migration and survival [15].

In murine research, the role of SAEs as inducer and modifier of disease has been demonstrated in models of airway disease [16,17], allergic asthma [18], atopic dermatitis [19] and food allergy [20]. These findings highlight the important pathological consequences of SAE exposure, as these superantigens not only cause massive T-cell stimulation, but also lead to activation of B-cells and other pro-inflammatory cells like neutrophils, eosinophils, macrophages and mast cells [21].

To date, the exact pathomechanisms of COPD are not yet elucidated. Cigarette smoking is a primary risk factor for the development of COPD, but only $20 \%$ of smokers actually develop the disease, suggesting that genetic predisposition plays a role [22]. However, understanding the impact of toxin-producing bacteria on cigarettesmoke induced inflammation might provide novel insights into the pathogenesis of smoking-related disease such as COPD. Therefore, we investigated the effects of concomitant Staphylococcus aureus Enterotoxin B (SEB) application on a well established mouse model of cigarette-smoke (CS) induced inflammation [23]. We evaluated inflammatory cells and their mediators in bronchoalveolar lavage (BAL) fluid and lung tissue, looked at systemic effects by measuring serum immunoglobulins, and evaluated goblet cell hyperplasia and lymphoid neogenesis.

\section{Methods}

\section{Experimental protocol}

Male C57BL/6 mice ( $\mathrm{n}=8$ ), 6-8 weeks old were purchased from Charles River Laboratories (Brussels, Belgium). Mice were exposed to the tobacco smoke of five cigarettes (Reference Cigarette 2R4F without filter, University of Kentucky, Lexington, KY, USA) four times per day with 30 min smoke-free intervals [24]. The animals were exposed to mainstream cigarette smoke (CS) by whole body exposure, 5 days per week for 4 weeks. Control groups (8 age-matched male C57BL/6 mice) were exposed to air. Starting from day 14 of the CS exposure, mice received concomitant endonasal application of SEB $(50 \mu \mathrm{L}-10 \mu \mathrm{g} / \mathrm{mL}$ - Sigma-Aldrich, LPS content below detection limit) or Saline, on alternate days. This dose was chosen based on Hellings et al. [18] For the application, mice were slightly anaesthetized with isoflurane, and six applications were performed as depicted in Figure 1. All experimental procedures were approved by the local ethical committee for animal experiments (Faculty of Medicine and Health Sciences, Ghent University). The results section contains data from one representative experiment out of three independent experiments.

\section{Bronchoalveolar lavage and cytospins}

Twenty-four hours after the last cigarette smoke (CS) exposure and endonasal application, mice were sacrificed by a lethal dose of pentobarbital (Sanofi-Synthelabo). A cannula was inserted in the trachea, and BAL was performed by instillation of $3 \times 300 \mu$ l of HBSS supplemented with BSA for cytokine measurements. Three additional instillations with $1 \mathrm{ml}$ of $\mathrm{HBSS}$ plus EDTA were performed to achieve maximal recovery of BAL cells. A total cell count was performed in a Bürker chamber. Approximately fifty thousand BAL cells were processed for cytospins and were stained with MayGrünwald-Giemsa for differential cell counting. The remaining cells were used for FACS analysis.

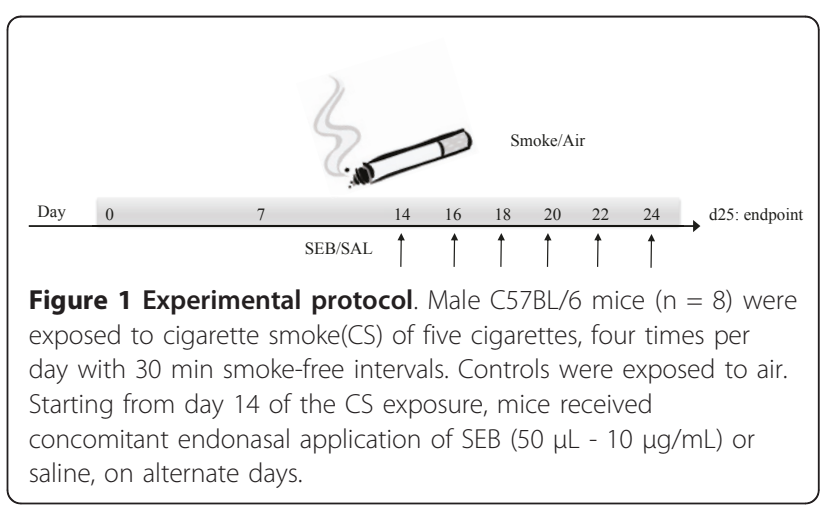




\section{Preparation of lung single-cell suspensions}

Blood was collected via retro-orbital bleeding. Then, the pulmonary and systemic circulation was rinsed to remove contaminating blood cells. Lungs were taken and digested as described previously [24]. Briefly, minced lung pieces were incubated with $1 \mathrm{mg} / \mathrm{ml}$ collagenase and $20 \mu \mathrm{g} / \mathrm{ml} \mathrm{DNase} \mathrm{I} \mathrm{for} 45 \mathrm{~min}$ at $37^{\circ} \mathrm{C}$. Red blood cells were lysed using ammonium chloride buffer. Finally, cell suspensions were filtered through a $50-\mu \mathrm{m}$ nylon mesh to remove undigested organ fragments.

\section{Flow cytometry}

All staining procedures were conducted in calcium- and magnesium-free PBS containing 10 mM EDTA, 1\% BSA (Dade Behring), and $0.1 \%$ sodium azide. Cells were preincubated with anti-CD16/CD32 (2.4G2) to block Fc receptors. Antibodies used to identify mouse DC populations were anti-CD11c-allophycocyanin (APC; HL3) and anti-I-Ab-phycoerythrin (PE; AF6-120.1). The following mAbs were used to stain mouse T-cell subpopulations: anti-CD4-fluorescein isothiocyanate (FITC; GK1.5), anti-CD8-FITC (53-6.7), anti-CD3-APC (1452C11) and anti-CD69-PE (H1.2F3). To identify granulocytes, anti-Gr-1-PE (RB6-8C5) and anti-CD11c-APC (HL3) were used. As a last step before analysis, cells were incubated with 7-aminoactinomycin D (or viaprobe; BD Pharmingen) for dead cell exclusion. All labeling reactions were performed on ice in FACS-EDTA buffer. Flow cytometry data acquisition was performed on a FACScalibur ${ }^{\mathrm{TM}}$ running CellQuest ${ }^{\mathrm{TM}}$ software (BD Biosciences, San Jose, CA, USA).

\section{Measurement of Immunoglobulins}

Retro-orbital blood was drawn for measurement of total IgE, IgG, IgM and IgA with ELISA. Commercially available ELISA kits were used to determine serum and BAL titers of IgG (ZeptoMetrix, Buffalo, NY, USA), IgM (ZeptoMetrix, Buffalo, NY, USA) and IgA (Alpha Diagnostic International, San Antonio, TX, USA). For the measurement of total IgE, a two-side in-house sandwich ELISA was used, with two monoclonal rat anti-mouse IgE antibodies reacting with different epitopes on the epsilon heavy chain (H. Bazin, Experimental Immunology Unit, UCL, Brussels, Belgium). The second antibody was biotinylated and detected colorimetrically after adding horseradish peroxidase-streptavidine conjugate. Absorbance values, read at $492 \mathrm{~nm}$ (Labsystems Multiscan RC, Labsystems b.v., Brussels, Belgium) were converted to concentrations in serum and BAL fluid by comparison with a standard curve obtained with mouse IgE of known concentration (H. Bazin)

\section{Goblet cell analysis}

Left lung was fixed in $4 \%$ paraformaldehyde and embedded in paraffin. Transversal sections of $3 \mu \mathrm{m}$ were stained with periodic acid-Schiff (PAS) to identify goblet cells. Quantitative measurements of goblet cells were performed in the airways with a perimeter of basement membrane $(\mathrm{Pbm})$ ranging from 800 to $2000 \mu \mathrm{m}$. Results are expressed as the number of goblet cells per millimeter of basement membrane.

\section{Morphometric quantification of lymphoid neogenesis}

To evaluate the presence of lymphoid infiltrates in lung tissues, sections obtained from formalin-fixed, paraffinembedded lung lobes were subjected to an immunohistological CD3/B220 double-staining as described previously [24]. Infiltrates in the proximity of airways and blood vessels were counted. Accumulations of $\geq 50$ cells were defined as lymphoid aggregates. Counts were normalized for the number of bronchovascular bundles per lung section.

\section{RT-PCR analysis}

Total lung RNA was extracted with the Rneasy Mini kit (Qiagen, Hilden, Germany). Expression of CXCL-13, CCL19, IL-13 and MIP-3 $\alpha$ mRNA relative to HPRT mRNA [25], were performed with Assay-on-demand Gene Expression Products (Applied Biosystems, Foster City, CA, USA). Real-time RT PCR for CCL21-leucine and CCL21-serine started from 25 ng of cDNA. Primers and FAM/TAMRA probes were synthesized on demand (Sigma-Proligo). Primer/probe sequences and PCR conditions were performed as described previously [26,27].

\section{Protein measurement in $\mathrm{BAL}$}

CXCL13 protein levels in BAL supernatant were determined using a commercially available ELISA (R\&D Systems, Abingdon, UK). Cytometric Bead Array (BD Biosciences, San Jose, CA, USA) was used to detect the cytokines KC, MCP-1, IL-17A and IFN- $\gamma$ in the supernatant of BAL fluid.

\section{Statistical analysis}

Reported values are expressed as mean \pm SEM. Statistical analysis was performed with SPSS software (version 18.0) using nonparametric tests. The different experimental groups were compared by a Kruskal-Wallis test for multiple comparisons. When a p-value $\leq 0.05$ was obtained with the Kruskal-Wallis test, pairwise comparisons were made by means of a Mann-Whitney $U$ test with Bonferroni corrections for multiple comparisons. A $\mathrm{p}$-value $\mathrm{p} \leq 0.05$ was considered significant. 


\section{Results}

SEB aggravates the CS-induced pulmonary inflammation

To evaluate the effects of Staphylococcus aureus enterotoxin B (SEB) on cigarette smoke (CS)-induced pulmonary inflammation, $\mathrm{C} 57 \mathrm{Bl} / 6$ mice were exposed to $\mathrm{CS}$ for 4 weeks, with a concomitant SEB exposure during the last 2 weeks (Figure 1).

In BAL fluid, sole endonasal SEB application and sole CS-exposure resulted in increased numbers of total cells, alveolar macrophages, dendritic cells (DCs), lymphocytes and neutrophils, compared to air/saline exposed animals (Figure 2A-E). However, these increases in cell numbers were much more pronounced upon SEB application compared to CS-exposure. Also a modest eosinophilic inflammation was observed in the SEBexposed groups (Figure 2F).

Interestingly, the combination of CS exposure and SEB significantly increased BAL neutrophil numbers compared to sole CS or SEB exposure (Figure 2E). Also BAL lymphocyte numbers in smoke-exposed mice were increased upon SEB application (Figure 2D).

In lung single cell suspensions, SEB solely induced an increase in $\mathrm{DCs}, \mathrm{CD}^{+} \mathrm{T}$ cells and macrophages, whereas CS exposure caused increased DCs and $\mathrm{CD}^{+}$ $\mathrm{T}$ cells in lung tissue (Figure $3 \mathrm{~A}, \mathrm{D}, \mathrm{B}$ ).

Interestingly, combined CS and SEB exposure caused a further increase in $\mathrm{CD}^{+} \mathrm{T}$ cells, and more specifically
$\mathrm{CD}^{+} \mathrm{T}$-cells, compared to CS or SEB alone (Figure 3D, F). Also DC, $\mathrm{CD} 4^{+} \mathrm{T}$-cells and $\mathrm{GR} 1^{+}$cells tended to be higher in the combined CS/SEB group versus sole CS or SEB application (Figure 3A, E, C).

\section{Increased IL-17A in BAL upon combined SEB and CS exposure}

As previously described [24], 4-wk CS-exposure clearly induced high levels of KC (mouse homolog for IL-8) and MCP-1 in BAL (Figure 4A, B). In contrast sole SEB application induced a modest increase in $\mathrm{KC}$, and very low levels of IFN- $\gamma$ and IL-17A (Figure 4A, D, C). Whereas the CS-induced KC and MCP-1 levels in BAL were not affected by an additional SEB exposure, the combined CS and SEB exposure did induce IL-17A levels in BAL, compared to single CS or SEB exposure (Figure 4C). Also IFN- $\gamma$ levels tended to be highest in the combined CS/SEB group (Figure 4D).

mRNA levels of MIP-3 $\alpha$ were increased after both CS or SEB exposure. Combined CS/SEB exposure did not cause a further MIP-3 $\alpha$ increase (Figure $4 \mathrm{E}$ ).

\section{SEB induces IgA and IgM levels in BAL}

Systemic effects of either CS or SEB, or both were evaluated in serum, but no significant differences in total IgG, IgM, IgA or IgE levels were detected between the experimental groups. In BAL, CS exposure tended to

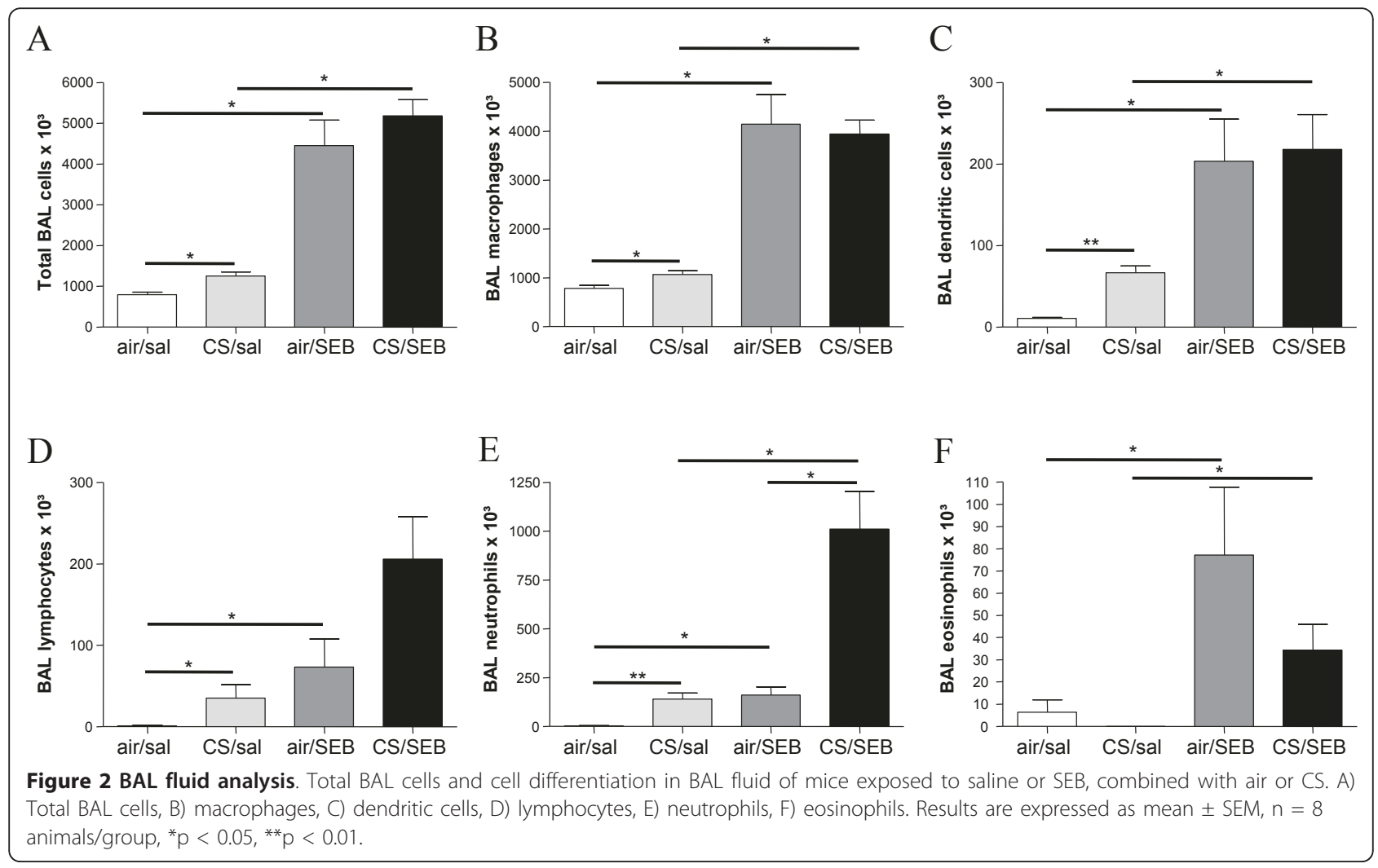



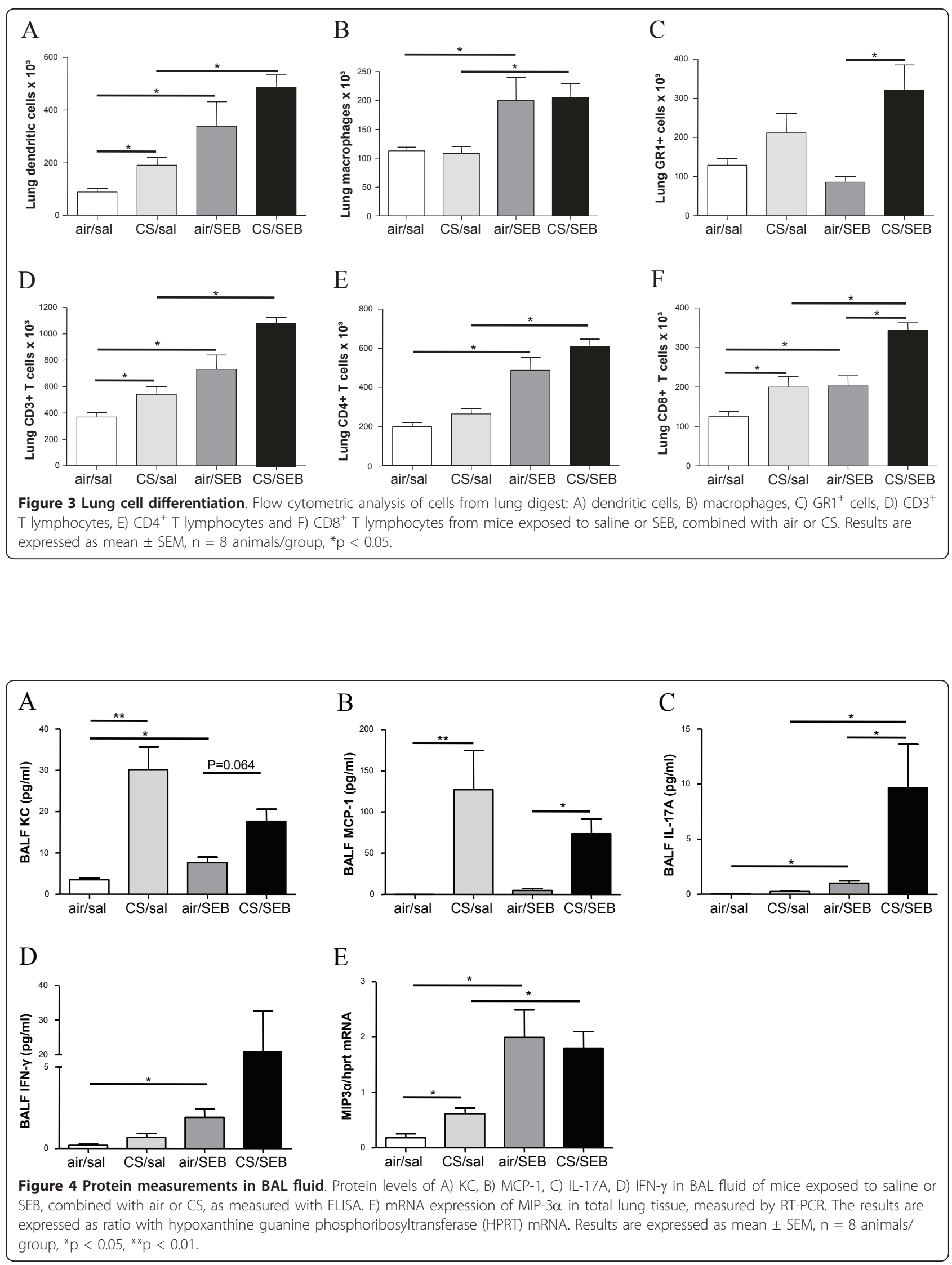


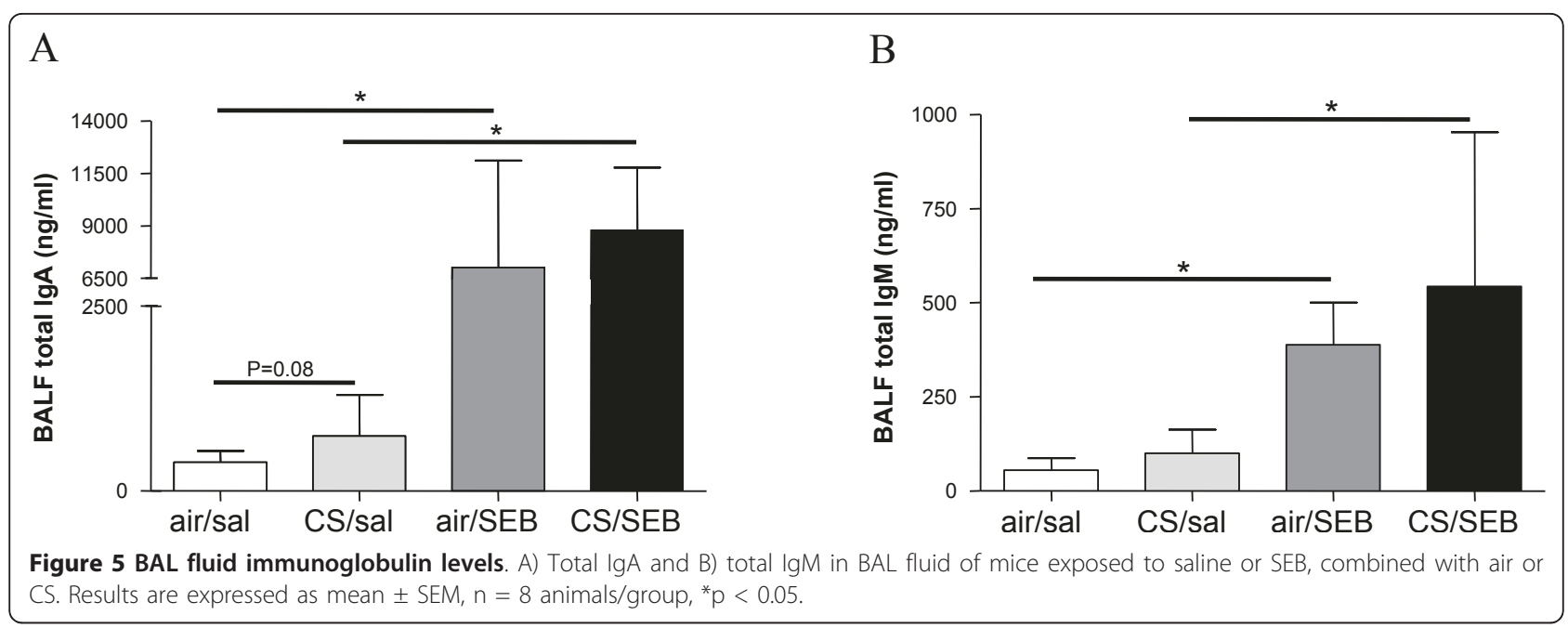

increase IgA. Both IgA and IgM levels in BAL were significantly increased upon SEB-exposure (Figure 5). IgE in BAL was below the detection limit.

\section{Combined CS/SEB exposure affects epithelial remodeling}

Epithelial remodeling was evaluated by counting the number of PAS-positive goblet cells per millimeter of basement membrane. A strong tendency towards increased numbers of goblet cells in the CS/SEB mice was observed, compared to all other conditions (Figure $6 \mathrm{~A}, \mathrm{~B})$. This finding correlated nicely with a significant increase in IL-13 mRNA expression in total lung in CS/ SEB mice (Figure 6C).

\section{Combined CS/SEB induces the formation of dense lymphoid aggregates in lung tissue}

Previously, our group has demonstrated increased lymphoid neogenesis after 6 months of CS-exposure [25]. As earlier shown in the CS-model, subacute CS-exposure as such did not result in lymphoid neogenesis. Interestingly however, already after 4-wk CS-exposure, dense, organized lymphoid aggregates could be demonstrated in the combined CS/SEB group whereas air/SEB mice displayed mainly loose, non-organized lymphoid aggregates (Figure 7).

Since CXCL13, CCL19 and CCL21 are chemokines involved in the homeostatic trafficking of leukocytes, mainly lymphocytes, to the secondary and tertiary lymphoid tissues, their expression was also evaluated in this model. The increase in dense lymphoid aggregates in CS/SEB mice correlated nicely with significant increases in CXCL13 (protein levels in BAL fluid, mRNA levels in total lung) (Figure 8A, B) and CCL19 (mRNA levels) expression in CS/SEB mice compared to all other groups (Figure 8E). CCL21 mRNA levels (both isoforms CCL21-Ser and CCL21-Leu) decreased upon CS exposure, confirming previous findings of CCL21 downregulation upon subacute CS exposure [26] and decreased even further in the CS/SEB group. Intriguingly, the CCL21 mRNA levels of both isoforms tended to increase upon sole SEB exposure (Figure 8C, D).

\section{Discussion}

We hereby describe a novel mouse model of combined Staphylococcus aureus enterotoxin B (SEB) application and cigarette smoke exposure, which results in a significant aggravation of key features of CS-induced pulmonary inflammation, such as neutrophils and $\mathrm{CD}^{+} \mathrm{T}$ cells in BAL and lung. Furthermore, levels of IL-17A in BAL were significantly increased upon concomitant SEB and CS exposure, compared to sole exposures of SEB or CS. In addition, tendencies of increased goblet cell hyperplasia, IL-13 mRNA expression and lymphoid neogenesis in smoke/SEB mice have been demonstrated, as well as increased expression of the relevant chemokines CXCL13 and CCL19. Altogether, these findings point to a possible disease-modifying role for SEB in CS-induced inflammation in this mouse model of subacute CS exposure.

Increasing evidence from human and murine research suggests that SEB is able to aggravate underlying disease. Moreover, SEB itself is also able to induce inflammation, depending on the dosage and timing of the experimental protocol $[16,19]$. Interestingly, these findings are not confined to SEB, as other staphylococcal superantigens demonstrate similar effects upon mucosal contact $[28,29]$. In line with previously reported findings, in our model sole endonasal SEB application caused an increase in total BAL cell number, lymphocytes and neutrophils [16]. Moreover, we could demonstrate raised numbers of macrophages and dendritic cells, a finding previously reported after $S$. aureus enterotoxin A 


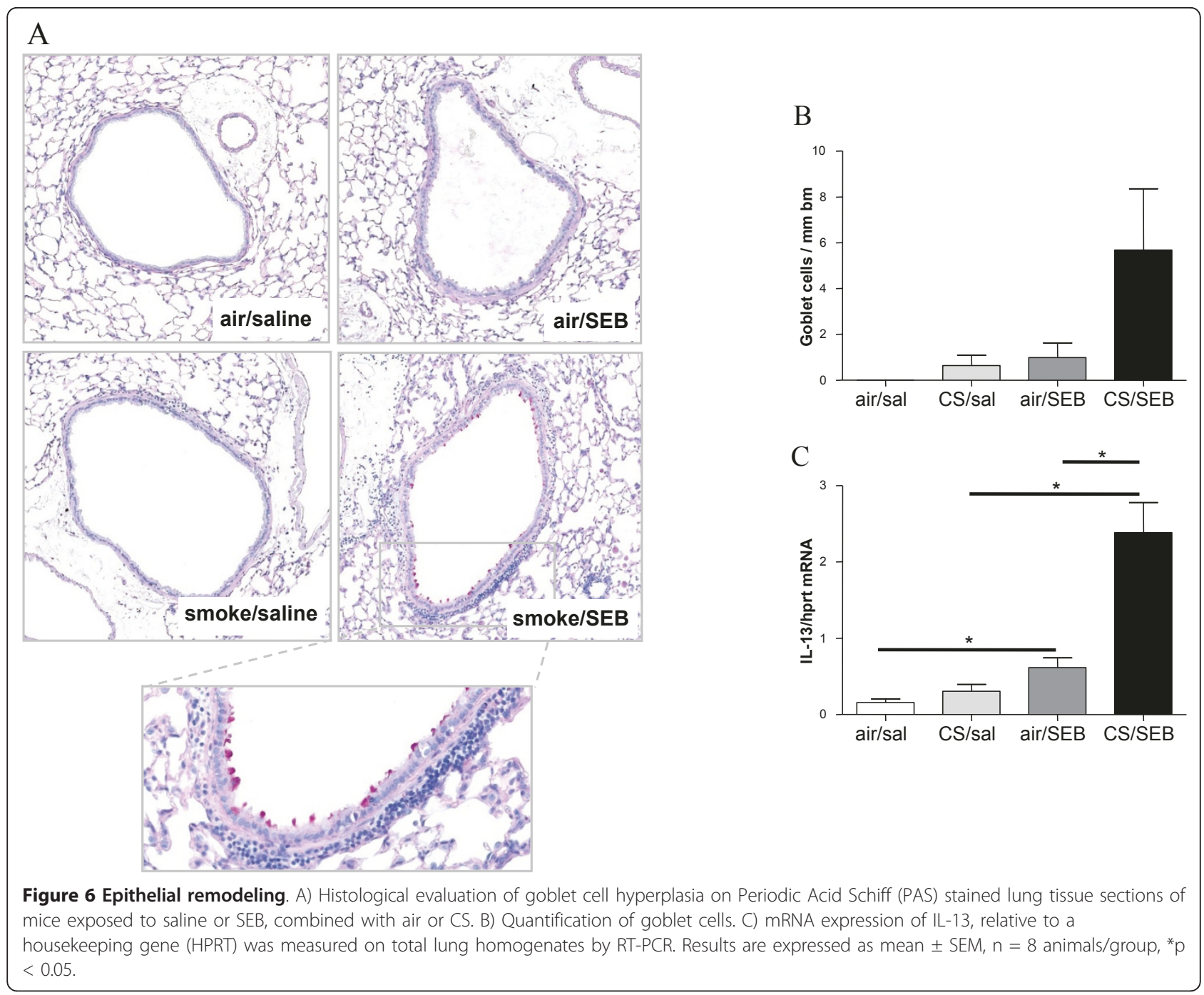

exposure $[28,29]$. In the latter studies however, the authors could not demonstrate increased eosinophils, which was the case in our model. The superantigen effect of SEB caused the expected lymphocyte accumulation in BAL, which appeared to be non-specific, as both $\mathrm{CD}^{+}$and $\mathrm{CD} 8^{+} \mathrm{T}$ cells were increased. These data stress the potency of staphylococcal superantigens of initiating a massive immune response.

Concomitant CS/SEB exposure lead to a remarkable increase in neutrophil number, compared to CS or SEB exposure alone. Although the findings for neutrophils in lung (measured with granulocyte marker GR-1) were less convincing than in BAL, the combined CS/SEB group showed the highest number of $\mathrm{GR}-1^{+}$cells. Interestingly, also the $\mathrm{CD}^{+} \mathrm{T}$ cell fraction in lung single cell suspensions, was significantly upregulated when smoke and SEB were combined. The potential clinical relevance of increased neutrophil and $\mathrm{CD}^{+} \mathrm{T}$-cell numbers lays in the fact that neutrophilic inflammation in the airways in smokers correlates with an accelerated decline in lung function [30], and increased T-cell numbers correlate with the amount of alveolar destruction and the severity of airflow obstruction [31].

We confirm an increased MIP-3 $\alpha$ expression in lungs after CS exposure leading to an accumulation of dendritic cells in this model [24]. Interestingly, this increase in MIP- $3 \alpha$ is also seen after SEB exposure, with raised DCs in BAL and airway parenchyma in these groups.

As previously demonstrated in the subacute CS-model, we have observed an increase in levels of $\mathrm{KC}$ and MCP1 after 4-wk CS exposure [24], explaining the accumulation of inflammatory cells in BAL and lung. Sole SEB application on the other hand resulted in raised levels of $\mathrm{KC}, \mathrm{IFN}-\gamma$ and IL-17A, but not MCP-1. Interestingly, the combined exposure of smoke and SEB further increased the IL-17A levels, which might explain the exacerbated BAL neutrophilia in CS/SEB mice. Indeed, IL-17 is known to be important in neutrophil 


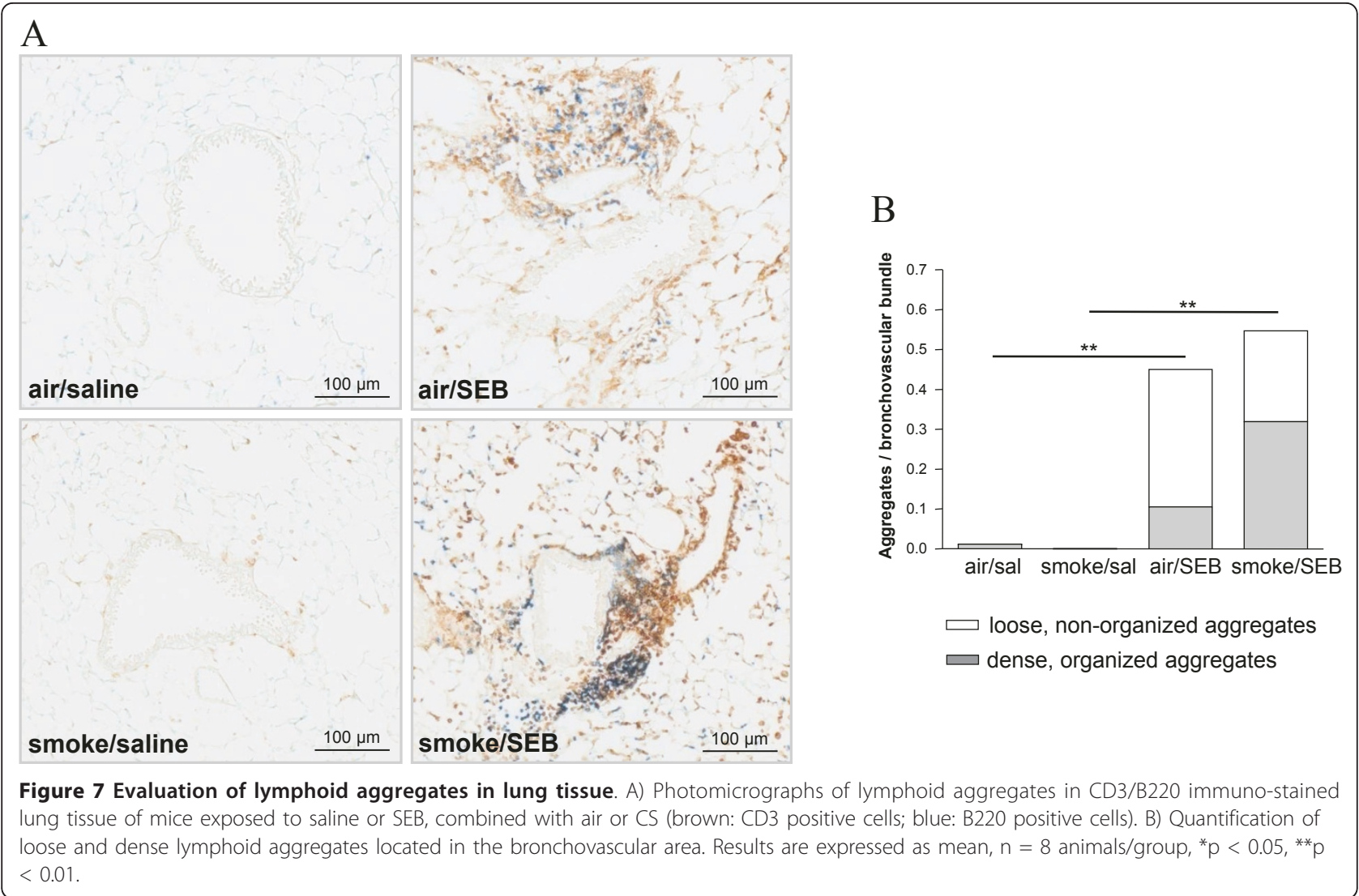

maturation, migration and function in the lung tissue and airways. Furthermore, IL-17 induction of neutrophil activation and migration is important in defense against organisms infecting the lung [32]. Interestingly, IL-17 can also induce eosinophilic accumulation, in particular circumstances [33].

IL-17 is normally produced by $\mathrm{CD} 4^{+} \mathrm{T}$ cells, although it might also arise from $\mathrm{CD} 8^{+} \mathrm{T}$ cells and in some cases even from macrophages, neutrophils or eosinophils [34], as a necessary step in the normal immunity against bacterial infections in the airways. However, IL-17 has been linked to unfavorable outcome to infection, in particular in the presence of IFN- $\gamma$ [35], resulting a high inflammatory pathology and tissue destruction. Increasing evidence dedicates a role to exaggerated recruitment and activation of neutrophils in the clinical course of airway diseases like COPD. Therefore, it is tempting to speculate on a role for SEB in the induction of IL-17 release, leading to the aggravation of cigarette smoke-induced inflammation, with increased number and activation of neutrophils, which causes amplification of tissue destruction and subsequent disease progression.

In addition, we could observe already after 4-wks an increase in the number of dense lymphoid aggregates in CS/SEB mice, linked to increased levels of CXCL13 and
CCL19, which are attractants for B- and T-cells respectively. Moreover, it has been described that the respective receptors for these chemokines - CXCR5 and CCR7 - are also expressed on Th17 cells migrating into inflamed tissue [36], indicating a potential contribution of IL17-producing Th17 cells in this model of early COPD. The finding that lymphoid aggregates and the chemokines responsible for their neogenesis and organization [25] are already upregulated after 4-wk CS/SEB exposure, stresses the clinical relevance of this novel model of combined CS and enterotoxin exposure.

Staphylococcal superantigens are able to cause massive polyclonal $\mathrm{T}$ and $\mathrm{B}$ cell proliferation. Upon local application, as is done in this model, this leads to the mucosal synthesis of immunoglobulins, explaining the observed increase in BAL IgA and IgM. In humans, it is thought that continuous microbial stimulation leads to B cell turnover and plasma cell formation in nasal polyp disease, leading to an overproduction of immunoglobulins [37].

In this mouse model of early stage COPD with goblet cell hyperplasia and increased number of lymphoid follicles, endonasal SEB application has resulted in augmented CS-induced lower airway inflammation. CS and subsequent bacterial colonization are, amongst others, factors believed to determine both progression of 

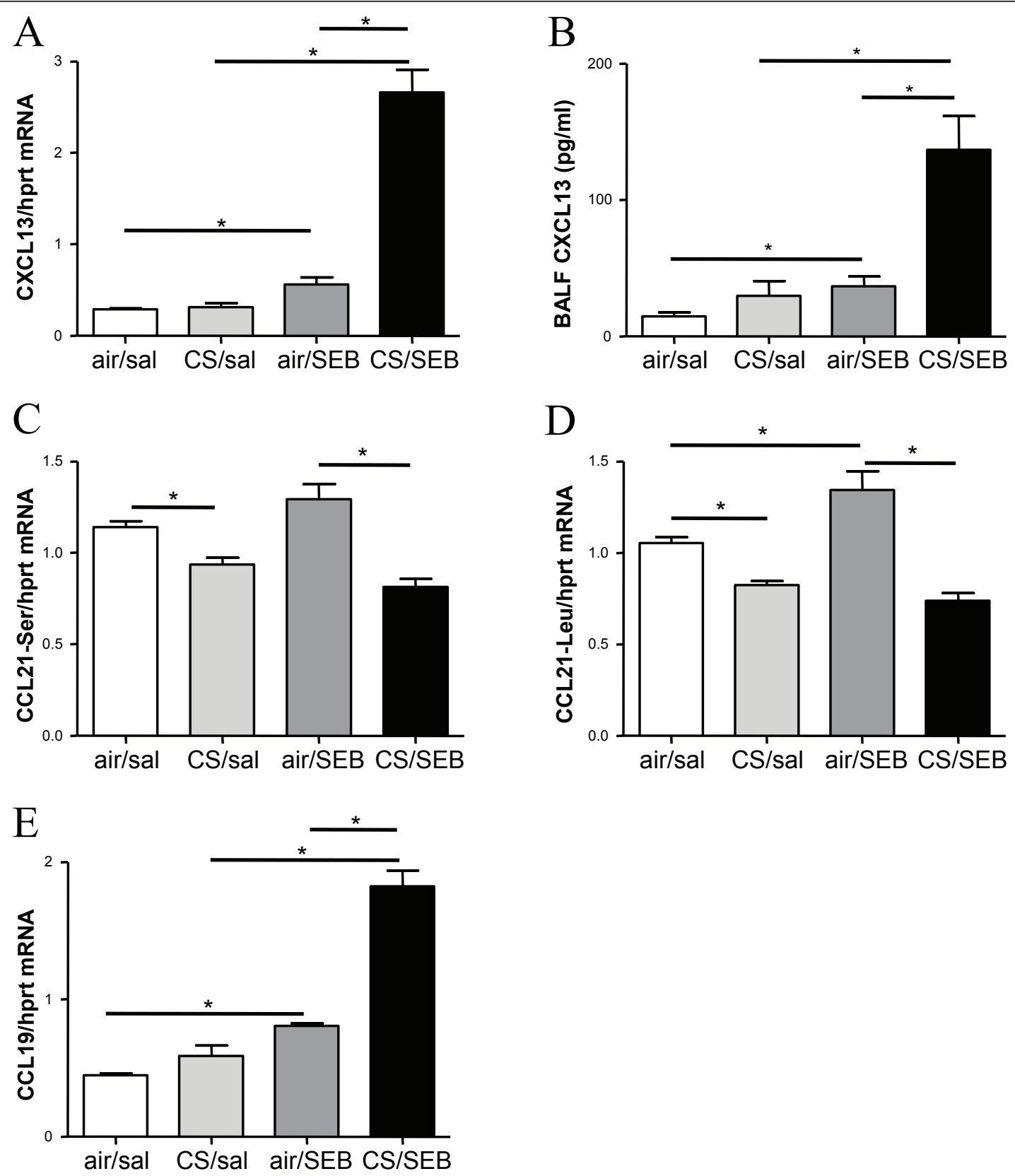

Figure 8 Chemokines involved in the homeostatic trafficking of leukocytes. Measurements of lymphoid chemokines in lung tissue and BAL fluid. mRNA expression of A) CXCL-13, C) CCL21-Ser, D) CCL21-Leu and E) CCL-19 in total lung tissue of mice exposed to saline or SEB, combined with air or CS, measured by RT-PCR. The results are expressed relative to HPRT mRNA. B) Protein levels of CXCL-13 in BAL fluid as measured by ELISA. Results are expressed as mean \pm SEM, $n=8$ animals/group, ${ }^{*} p<0.05$.

COPD, as well as the frequency and severity of COPD exacerbations [38]. Therefore, mouse models of CS and bacterial co-exposure have been used in the past, mainly using Haemophilus influenzae [39]. Bacterial colonization and infection is rare in lower airways, but not in upper airways. Local carriage of enterotoxin-producing $S$. aureus in the nasal cavity is common, although multiple sites can be colonized (e.g. skin, pharynx and perineum) [40]. These toxins, like toxic shock syndrome toxin-1 (TSST-1), are known superantigens causing systemic diseases like food poisoning and toxic shock syndrome [4]. In nasal polyp disease, these toxins are believed to drive the local immunoglobulin production in response to enterotoxin-producing $S$. aureus.

The use of a single toxin instead of $S$. aureus in this model is both a strength and a limitation, since it 
simplifies the interpretation on one hand, but is not the real life situation on the other hand. Another limitation is that we cannot rule out endotoxin related effects in our model, although the LPS content of our SEB was below detection limit. Also the potential differences between our mouse model and the human situation concerning exposure to bacterial toxins and its effects on the balance of cytokines and inflammation is a limitation of the study. In addition, SEB on itself has resulted in pronounced inflammation in BAL and lungs, as it is a known superantigen. Finally, another possible limitation of this model is the short term (4-wk) CS exposure, whereas COPD is a chronic disease. Despite these limitations, altogether our findings indicate the importance of bacterial toxins present in the upper airways, affecting lower airway inflammation.

\section{Conclusion}

The possible disease-modifying role for SAEs in COPD that has been described in humans [14], combined with our findings stress the potential role of airway colonizing and toxin-producing Staphylococcus aureus, in the pathophysiology of COPD [3].

\section{Acknowledgements}

The authors would like to thank Greet Barbier, Eliane Castrique, Indra De Borle, Philippe De Gryze, Katleen De Saedeleer, Anouck Goethals, Marie-Rose Mouton, Ann Neessen, Christelle Snauwaert and Evelyn Spruyt for their technical assistance.

This project is supported by the Fund for Scientific Research - Flanders (FWO-Vlaanderen - Project G.0052.06), by a grant from the Ghent University (BOF/GOA 01251504), by the Interuniversity Attraction Poles program (IUAP) - Belgian state - Belgian Science Policy P6/35, and by grants to CB from the Fund for Scientific Research - Flanders, FWO, no. A12/5-HB-KH3 and G.0436.04, and to KB as a postdoctoral fellow of the Fund for Scientific Research Flanders (FWO).

\section{Author details}

${ }^{1}$ Upper Airways Research Laboratory (URL), ENT Department, Ghent University Hospital, Ghent University, Belgium. ²Department of Respiratory Medicine, Ghent University Hospital and Ghent University, Ghent, Belgium. ${ }^{3}$ Department of Pathology, Ghent University Hospital, Ghent University, Belgium. ${ }^{4}$ Laboratory of Experimental Immunology, University Hospitals Leuven, Catholic University Leuven, Leuven, Belgium.

\section{Authors' contributions}

WH carried out the design and coordination of the study, gathered the data and interpreted the data, drafted and finalized the manuscript. EL gathered the data and interpreted the data, drafted and revised the manuscript. OK gathered the data and was involved in the critical reading of the manuscript. TD helped to optimize the PCR analyses for CXCL13 and CCL19. $\mathrm{KB}, \mathrm{PH}, \mathrm{GB}, \mathrm{GJ}$ and $\mathrm{CB}$ were involved in the coordination and design of the study as well as the critical reading of the manuscript. TM participated in the coordination of the study, helped to interpret the data and critically revised the manuscript. All authors read and approved the final version of the manuscript.

\section{Competing interests}

The authors declare that they have no competing interests.

Received: 24 January 2011 Accepted: 27 May 2011 Published: 27 May 2011

\section{References}

1. Drannik AG, Pouladi MA, Robbins CS, Goncharova SI, Kianpour S, Stampfli MR: Impact of cigarette smoke on clearance and inflammation after Pseudomonas aeruginosa infection. Am J Respir Crit Care Med 2004, 170:1164-1171.

2. Soler N, Ewig S, Torres A, Filella X, Gonzalez J, Zaubet A: Airway inflammation and bronchial microbial patterns in patients with stable chronic obstructive pulmonary disease. Eur Respir J 1999, 14:1015-1022.

3. Sethi S, Murphy TF: Infection in the pathogenesis and course of chronic obstructive pulmonary disease. N Engl J Med 2008, 359:2355-2365.

4. Fraser JD, Proft $\mathrm{T}$ : The bacterial superantigen and superantigen-like proteins. Immunol Rev 2008, 225:226-243.

5. Sundberg EJ, Deng L, Mariuzza RA: TCR recognition of peptide/MHC class II complexes and superantigens. Semin Immunol 2007, 19:262-271.

6. Chau TA, McCully ML, Brintnell W, An G, Kasper KJ, Vines ED, Kubes P, Haeryfar SM, McCormick JK, Cairns E, et al: Toll-like receptor 2 ligands on the staphylococcal cell wall downregulate superantigen-induced T cell activation and prevent toxic shock syndrome. Nat Med 2009, 15:641-648.

7. Bachert C, Gevaert P, Zhang N, van Zele T, Perez-Novo C: Role of staphylococcal superantigens in airway disease. Chem Immunol Allergy 2007, 93:214-236.

8. Rossi RE, Monasterolo G: Prevalence of serum lgE antibodies to the Staphylococcus aureus enterotoxins (SAE, SEB, SEC, SED, TSST-1) in patients with persistent allergic rhinitis. Int Arch Allergy Immunol 2004, 133:261-266.

9. Bachert C, Zhang N, Patou J, van Zele T, Gevaert P: Role of staphylococcal superantigens in upper airway disease. Curr Opin Allergy Clin Immunol 2008, 8:34-38.

10. Heaton T, Mallon D, Venaille T, Holt P: Staphylococcal enterotoxin induced IL-5 stimulation as a cofactor in the pathogenesis of atopic disease: the hygiene hypothesis in reverse? Allergy 2003, 58:252-256.

11. Breuer K, Kapp A, Werfel T: Bacterial infections and atopic dermatitis. Allergy 2001, 56:1034-1041.

12. Carayol N, Crampette L, Mainprice B, Ben-Soussen P, Verrecchia M, Bousquet J, Lebel B: Inhibition of mediator and cytokine release from dispersed nasal polyp cells by mizolastine. Allergy 2002, 57:1067-1070.

13. Bachert C, Gevaert P, Holtappels G, Johansson SG, Van Cauwenberge P: Total and specific IgE in nasal polyps is related to local eosinophilic inflammation. J Allergy Clin Immunol 2001, 107:607-614.

14. Rohde G, Gevaert P, Holtappels G, Borg I, Wiethege A, Arinir U, SchultzeWerninghaus G, Bachert C: Increased IgE-antibodies to Staphylococcus aureus enterotoxins in patients with COPD. Respir Med 2004, 98:858-864

15. Huvenne W, Callebaut I, Reekmans K, Hens G, Bobic S, Jorissen M, Bullens DM, Ceuppens JL, Bachert C, Hellings PW: Staphylococcus aureus enterotoxin $B$ augments granulocyte migration and survival via airway epithelial cell activation. Allergy 2010, 65:1013-1020.

16. Herz U, Ruckert R, Wollenhaupt K, Tschernig T, Neuhaus-Steinmetz U, Pabst R, Renz H: Airway exposure to bacterial superantigen (SEB) induces lymphocyte-dependent airway inflammation associated with increased airway responsiveness - a model for non-allergic asthma. Eur J Immunol 1999, 29:1021-1031.

17. Huvenne W, Callebaut I, Plantinga M, Vanoirbeek JA, Krysko O, Bullens DM, Gevaert P, Van Cauwenberge P, Lambrecht BN, Ceuppens $J$, et al: Staphylococcus aureus enterotoxin B facilitates allergic sensitization in experimental asthma. Clin Exp Allergy 2010, 40:1079-1090.

18. Hellings PW, Hens G, Meyts I, Bullens D, Vanoirbeek J, Gevaert P, Jorissen M Ceuppens $\lrcorner$, Bachert $C$ : Aggravation of bronchial eosinophilia in mice by nasal and bronchial exposure to Staphylococcus aureus enterotoxin B. Clin Exp Allergy 2006, 36:1063-1071.

19. Laouini D, Kawamoto S, Yalcindag A, Bryce P, Mizoguchi E, Oettgen H, Geha RS: Epicutaneous sensitization with superantigen induces allergic skin inflammation. J Allergy Clin Immunol 2003, 112:981-987.

20. Ganeshan K, Neilsen CV, Hadsaitong A, Schleimer RP, Luo X, Bryce PJ: Impairing oral tolerance promotes allergy and anaphylaxis: a new murine food allergy model. J Allergy Clin Immunol 2009, 123:231-238.

21. Marone G, Rossi FW, Detoraki A, Granata F, Marone G, Genovese A, Spadaro G: Role of superallergens in allergic disorders. Chem Immunol Allergy 2007, 93:195-213.

22. Fletcher $\mathrm{C}$, Peto R: The natural history of chronic airflow obstruction. $\mathrm{Br}$ Med J 1977, 1:1645-1648. 
23. D'Hulst Al, Vermaelen KY, Brusselle GG, Joos GF, Pauwels RA: Time course of cigarette smoke-induced pulmonary inflammation in mice. Eur Respir J 2005, 26:204-213.

24. Bracke KR, D'Hulst A I, Maes T, Moerloose KB, Demedts IK, Lebecque S, Joos GF, Brusselle GG: Cigarette smoke-induced pulmonary inflammation and emphysema are attenuated in CCR6-deficient mice. J Immunol 2006, 177:4350-4359.

25. Demoor T, Bracke KR, Maes T, Vandooren B, Elewaut D, Pilette C, Joos GF, Brusselle GG: Role of lymphotoxin-alpha in cigarette smoke-induced inflammation and lymphoid neogenesis. Eur Respir J 2009, 34:405-416.

26. Demoor T, Bracke KR, Vermaelen KY, Dupont L, Joos GF, Brusselle GG: CCR7 modulates pulmonary and lymph node inflammatory responses in cigarette smoke-exposed mice. J Immunol 2009, 183:8186-8194.

27. Chen SC, Vassileva G, Kinsley D, Holzmann S, Manfra D, Wiekowski MT, Romani N, Lira SA: Ectopic expression of the murine chemokines CCL21a and CCL21b induces the formation of lymph node-like structures in pancreas, but not skin, of transgenic mice. J Immunol 2002, 168:1001-1008.

28. Muralimohan G, Rossi RJ, Guernsey LA, Thrall RS, Vella AT: Inhalation of Staphylococcus aureus enterotoxin A induces IFN-gamma and CD8 T cell-dependent airway and interstitial lung pathology in mice. J Immunol 2008, 181:3698-3705.

29. Muralimohan G, Rossi RJ, Vella AT: Recruitment and in situ renewal regulate rapid accumulation of $\mathrm{CD} 11 \mathrm{c}+$ cells in the lung following intranasal superantigen challenge. Int Arch Allergy Immunol 2008, 147:59-73.

30. Stanescu D, Sanna A, Veriter C, Kostianev S, Calcagni PG, Fabbri LM Maestrelli P: Airways obstruction, chronic expectoration, and rapid decline of FEV1 in smokers are associated with increased levels of sputum neutrophils. Thorax 1996, 51:267-271.

31. Barnes PJ, Shapiro SD, Pauwels RA: Chronic obstructive pulmonary disease: molecular and cellular mechanisms. Eur Respir J 2003, 22:672-688.

32. Linden A, Laan M, Anderson GP: Neutrophils, interleukin-17A and lung disease. Eur Respir J 2005, 25:159-172.

33. Wakashin $H$, Hirose K, Maezawa $Y$, Kagami S, Suto A, Watanabe N, Saito $Y$, Hatano M, Tokuhisa T, Iwakura Y, et al: IL-23 and Th17 cells enhance Th2cell-mediated eosinophilic airway inflammation in mice. Am J Respir Crit Care Med 2008, 178:1023-1032.

34. Mucida D, Salek-Ardakani S: Regulation of TH17 cells in the mucosal surfaces. J Allergy Clin Immunol 2009, 123:997-1003.

35. Zelante T, De Luca A, Bonifazi P, Montagnoli C, Bozza S, Moretti S, Belladonna ML, Vacca C, Conte C, Mosci P, et al: IL-23 and the Th17 pathway promote inflammation and impair antifungal immune resistance. Eur J Immunol 2007, 37:2695-2706.

36. Kim CH: Migration and function of Th17 cells. Inflamm Allergy Drug Targets 2009, 8:221-228.

37. Van Zele T, Gevaert P, Holtappels G, van Cauwenberge P, Bachert C: Local immunoglobulin production in nasal polyposis is modulated by superantigens. Clin Exp Allergy 2007, 37:1840-1847.

38. Gaschler GJ, Bauer CM, Zavitz CC, Stampfli MR: Animal models of chronic obstructive pulmonary disease exacerbations. Contrib Microbiol 2007, 14:126-141.

39. Gaschler GJ, Skrtic M, Zavitz CC, Lindahl M, Onnervik PO, Murphy TF, Sethi S, Stampfli MR: Bacteria challenge in smoke-exposed mice exacerbates inflammation and skews the inflammatory profile. Am J Respir Crit Care Med 2009, 179:666-675.

40. Wertheim HF, Melles DC, Vos MC, van Leeuwen W, van Belkum A, Verbrugh HA, Nouwen $J$ : The role of nasal carriage in Staphylococcus aureus infections. Lancet Infect Dis 2005, 5:751-762.

doi:10.1186/1465-9921-12-69

Cite this article as: Huvenne et al:: Exacerbation of cigarette smokeinduced pulmonary inflammation by Staphylococcus aureus Enterotoxin B in mice. Respiratory Research 2011 12:69.

\section{Submit your next manuscript to BioMed Central and take full advantage of:}

- Convenient online submission

- Thorough peer review

- No space constraints or color figure charges

- Immediate publication on acceptance

- Inclusion in PubMed, CAS, Scopus and Google Scholar

- Research which is freely available for redistribution

Submit your manuscript at www.biomedcentral.com/submit
Biomed Central 